\title{
PRODUÇÃO, TEOR FOLIAR E QUALIDADE DE FRUTOS DO PESSEGUEIRO 'CHIMARRITA' EM FUNÇÃO DA ADUBAÇÃO NITROGENADA, NA REGIÃO DA LAPA-PR ${ }^{1}$
}

\author{
MARCOS ANTONIO DOLINSKI ${ }^{2}$, BEATRIZ MONTE SERRAT ${ }^{3}$, ANTONIO CARLOS VARGAS MOTTA ${ }^{3}$, FRANCINE \\ LORENA CUQUEL ${ }^{4}$, SILVANA REGINA DE SOUZA ${ }^{5}$, LOUISE LARISSA MAY-DE MIO ${ }^{4}$, \\ LINO BITTENCOURT MONTEIRO ${ }^{4}$
}

\begin{abstract}
RESUMO - A produção integrada de pêssego (Prunus persica L. Batsch) regulamenta a dose de $\mathrm{N}$ a ser aplicada, a fim de manter a produtividade, sem afetar a sanidade da planta e a qualidade ambiental. Contudo, existe uma grande carência de informação sobre a dose de $\mathrm{N}$ necessária na manutenção da produtividade de pomares na região da Lapa. Assim, avaliaram-se doses de $\mathrm{N}$ na produção, no teor foliar e na qualidade de frutos da cultivar 'Chimarrita', por três anos, em um pomar comercial com 5 anos de idade, localizado no município da Lapa-PR. O delineamento experimental foi em blocos ao acaso, com três tratamentos e três repetições. Os tratamentos consistiram de doses de N (40; 80 e $\left.160 \mathrm{~kg} \mathrm{de} \mathrm{N} \mathrm{ha-1} \mathrm{ano}^{-1}\right)$, na forma de uréia. A redução na adubação nitrogenada em pomar estabelecido afetou negativamente a produtividade para o segundo ano. Com um decréscimo acumulado de 8,4 t ha $^{-1} \mathrm{em}$ três anos, para a menor dose quando comparada com a maior dose. A produtividade variou com o número de frutos, visto que a massa média dos frutos e o calibre não foram suficientes para afetar a produção. A adubação de $\mathrm{N}$ não afetou os aspectos qualitativos dos frutos avaliados (sólidos solúveis totais, acidez total titulável e firmeza da polpa), que ficaram em geral dentro dos padrões normais da cultivar. Para os teores foliares, somente o $\mathrm{N}$ foi afetado pela adubação nitrogenada para os três anos avaliados, mas ficando para todos os tratamentos em níveis considerados normais. Os teores foliares de $\mathrm{Ca}, \mathrm{Mg}$, Fe e $\mathrm{Zn}$ ficaram abaixo do preconizado para o pêssego.
\end{abstract}

Termos de indexação: Prunus persica, pêssego, nutrição, nitrogênio.

\section{PRODUCTION, LEAVES CONCENTRACION AND FRUIT QUALITY OF THE PEACH ORCHARD 'CHIMARRITA' AS FUNCTION OF N FERTILIZATION, AT LAPA REGION, PARANA STATE - BRAZIL}

\begin{abstract}
The peach (Prunus persica L. Batsch) integrated production regulates the $\mathrm{N}$ rates to be applied in order to obtain high yield and fruit quality without affecting plant sanity and environmental quality. However, there is a great lack of local information about $\mathrm{N}$ rate that it is necessary to achieve high yield for orchard at Lapa origin. So, an experiment was implanted in 5-year old commercial orchard, in the Lapa County, Paraná State, Brazil where it was evaluated $\mathrm{N}$ rates effect over the fruit yield, leaves concentration and quality, during three years. The experimental design was a randomized block with three treatments and three replications. The treatments were three $\mathrm{N}$ rates $\left(40,80\right.$ and $160 \mathrm{~kg}^{\circ} \mathrm{N} \mathrm{ha}^{-1}$ ano-1), using urea as $\mathrm{N}$ source. The reduction in nitrogen fertilization, in established orchard, diminished the yield only for the second year. There was an accumulated yield decrease of $8,4 \mathrm{t} \mathrm{ha}^{-1}$ during three years, comparing the smallest to largest rate. The yield was straight associated with fruit number since the fruit mass and caliber were not affected by $\mathrm{N}$ application. The $\mathrm{N}$ fertilization did not effect fruit qualitative proprieties evaluated (total soluble solids, acidity total titratable and firmness of the pulp) and them values stayed within range concentration considered normal for cultivar. Leave tissue analysis showed that only $\mathrm{N}$ concentration was affected by the $\mathrm{N}$ fertilization for the three evaluated years, but being in normal levels for all treatments. The $\mathrm{Ca}, \mathrm{Mg}, \mathrm{Fe}$ and $\mathrm{Zn}$ leaves concentration was below normal level established for peach..
\end{abstract}

Index Terms: Prunus persica, peach, nutrition, nitrogen.

\section{INTRODUÇÃO}

A produção e a área mundial com o cultivo de pêssego (Prunus persica L. Batsch) quase quadruplicaram nos últimos quarenta anos, embora tenha ocorrido, nesse mesmo período, diminuição na produtividade (FAO, 2003). O Brasil não está entre os principais países produtores mundiais dessa fruta, ocupando a décima segunda posição em produção, e a vigésima segunda em produtividade, com média dos últimos cinco anos de $8 \mathrm{t} \mathrm{ha}^{-1}$, enquanto países como a França, EUA, Grécia, Espanha e Itália apresentam produtividades médias superiores a $15 \mathrm{tha}^{-1}$ (FAO, 2003).

O Estado do Paraná, em 2003, possuía 1.985 hectares plantados com a cultura do pêssego, com produtividade média de 9,2 $\mathrm{t} \mathrm{ha}^{-1}$ (Madail $\&$ Reichert, 2003). Contudo, não são raros os casos de produtividades maiores que $25 \mathrm{t} \mathrm{ha}^{-1}$ de frutos, indicando grande potencial da cultura quando adequadamente manejada e sob condições climáticas favoráveis.

A baixa produtividade dos pomares paranaenses pode ser atribuída em parte ao uso de baixas doses de corretivos e de fertilizantes, especialmente o nitrogênio. Em levantamento realizado na região Sul do
Paraná, foi constatada grande variação quanto às doses de adubos nitrogenados aplicadas pelos produtores, variando de 30 a $150 \mathrm{~kg}$ de $\mathrm{N}$ ha $^{-1}$ ano $^{-1}$, indicando grande carência de informação sobre dose de $\mathrm{N}$ necessária na manutenção da produtividade de pomares na região (PIFPR-CNPq, 2003). A maior dose utilizada fica próxima à recomendada para o Estado de São Paulo (Ojima et al., 1997). Já as Normas para a Produção Integrada de Pêssegos, em 2002, no início da implantação do experimento, recomendava que não fosse ultrapassada a dose de $80 \mathrm{~kg}$ de $\mathrm{N} \mathrm{ha}^{-1}$ ano $^{-1}$ (Normas de Produção Integrada de Pêssego, 2001).

O nitrogênio é o elemento considerado de maior influência na produtividade do pessegueiro (Rombolà et al., 2000), por afetar diretamente o crescimento dos ramos (Mattos et al., 1991b e Campos et al., 1996), o número de gemas floríferas e vegetativas (Mattos et al., 1991b) e o número de frutos por planta (Mattos et al., 1991b). Esse elemento pode propiciar um período maior de manutenção das folhas, com conseqüente aumento no período de acúmulos de reservas para o ciclo posterior (Serrat et al., 2004). No entanto, o suprimento excessivo pode levar ao superbrotamento, provocando o sombreamento excessivo e diminuindo a insolação dos frutos (Mattos et al., 1991b).

$\mathrm{O}$ uso de $\mathrm{N}$ pode interferir ainda no aspecto qualitativo da

\footnotetext{
(Trabalho 135/2004). Recebido: 21/10/2004. Aceito para publicação: 24/08/2005. Pesquisa financiada pelo MAPA.

${ }^{2}$ Graduando do curso de Agronomia, Bolsista de Iniciação Científica-PIBIC/CNPq, Universidade Federal do Paraná/UFPR. marcosagro@pop.com.br. Autor para correspondência.

${ }^{3}$ Eng. Agrônomo, Dr., Professor do Departamento de Solos e Engenharia Agrícola da UFPR, Rua dos Funcionários, 1540 Bairro Juvevê, CEP 80035-050, CuritibaPR.mottaacv@ufpr.br.

${ }^{4}$ Eng. Agrônomo, Dr., Professor do Departamento de Fitotecnia e Fitossanitarismo da UFPR maydemio@ufpr.br.

${ }^{5}$ Eng. Agrônoma, Mestranda em Agronomia da UFPR, Programa de Pós-graduação em Ciência do solo-mestrado.
} 
produção (Pereira et al., 1994), afetando o tamanho dos frutos (Mattos et al., 1991b), a coloração da casca (Reeves \& Cummings, 1970), a firmeza da polpa e a porcentagem de sólidos solúveis totais (Campos et al., 1996).

A produtividade e a qualidade de frutos podem ser afetadas pela seleção de cultivar. A cultivar 'Chimarrita' é bastante difundida no Sul do Brasil, apresentando grande importância e crescimento do plantio no Estado do Paraná, dadas as altas produtividades e a baixa necessidade em frio (Biasi et al., 2004). A colheita dessa cultivar é feita entre o final de novembro e a primeira quinzena de dezembro, sendo que os frutos apresentam, normalmente, massa superior a 100 gramas e sólidos solúveis totais variando de 12 a $15^{\circ}$ Brix (Raseira \& Nakasu, 1998).

A dose a ser recomendada para cada região deverá ser criteriosa, pois o efeito da adubação nitrogenada não se restringe apenas a parâmetros de produtividade e qualidade, mas também a parâmetros ambientais, tais como elevação dos níveis de nitrato no lençol freático e eutrofização de lagos e rios (Motta et al., 2004). A produção integrada de pêssego regulamenta a dose de $\mathrm{N}$ a ser aplicado, a fim de manter a produtividade, sem afetar a sanidade da planta e a qualidade ambiental (Fachinello et al., 2004).

O objetivo deste trabalho foi avaliar, por três anos, o efeito da adubação nitrogenada na produção, teores foliares e qualidade de frutos da cultura do pessegueiro, comparando os limites das doses utilizadas na região e a máxima recomendada em 2002 pelas Normas da Produção Integrada de Pêssego.

\section{MATERIAL E MÉTODOS}

O experimento foi instalado no início de 2002, em um pomar comercial de pessegueiro 'Chimarrita', com cinco anos de idade, no Município da Lapa (PR). A altitude do local é $900 \mathrm{~m}$ e o clima classificado (Köppen) como $\mathrm{Cfb}$ (subtropical úmido), com temperatura média de $20,4^{\circ} \mathrm{C}$ no verão, e $12,7^{\circ} \mathrm{C}$ no inverno, apresentando precipitação média entre $1.400 \mathrm{a} 1.600 \mathrm{~mm}^{2} \mathrm{ano}^{-1}$, com ocorrência de geada e granizo.

No primeiro ano do experimento, ocorreu adversidade climática, caracterizada pela ocorrência de geada na primeira semana de setembro de 2002, acarretando abortamento e queda de frutos. No terceiro ano do experimento, foi realizada pelo produtor uma poda de inverno intensa.

A área experimental compreendia 216 plantas, conduzidas no sistema de vaso, com 4 linhas espaçadas de 6 metros, e 3 metros entre plantas, com 24 plantas por parcela, totalizando 0,56 ha. As coletas de dados foram realizadas nas duas linhas centrais, em oito plantas localizadas na área útil de cada parcela.

O delineamento experimental foi em blocos ao acaso, com três tratamentos e três repetições. Os tratamentos consistiram de doses de $\mathrm{N}\left(40 ; 80\right.$ e $\left.160 \mathrm{~kg} \mathrm{de} \mathrm{ha}^{-1} \mathrm{ano}^{-1}\right)$, na forma de uréia, que foram parceladas em três períodos: início da brotação (30\%), após o raleio (30\%) e após a colheita (40\%). A adubação potássica foi de $80 \mathrm{~kg}$ de $\mathrm{K}_{2} \mathrm{O} \mathrm{ha}^{-1} \mathrm{ano}^{-1}$, na forma de Cloreto de Potássio, parcelada em dois períodos: durante o inverno (60\%) e após o raleio (40\%). No primeiro ano de implantação do experimento, foram aplicados $120 \mathrm{~kg}$ de $\mathrm{P}_{2} \mathrm{O}_{5} \mathrm{ha}^{-1}$ no inverno, na forma de Superfosfato Simples em área total. Já no segundo e terceiro anos, $22 \mathrm{~kg}$ de $\mathrm{P}_{2} \mathrm{O}_{5}$ ha $^{-1}$ no inverno. A adubação foi realizada manualmente, na área de projeção da copa.

A análise de solo foi realizada anteriormente à implantação do experimento, em amostra composta, obtida de vinte amostras simples por parcela, coletadas da projeção da copa, na profundidade de $0-20 \mathrm{~cm}$, conforme metodologia descrita pela Comissão de Fertilidade do Solo (1995). O solo é classificado como Cambissolo, e os atributos químicos e físicos estão apresentados na Tabela 1.

As podas (inverno e verão) e o raleio foram realizados conforme o manejo adotado pela propriedade. A poda de verão, com o objetivo de retirar os ramos "ladrões", foi realizada quinze dias antes da colheita, avaliada através da massa total do material podado. O controle de pragas, doenças e plantas invasoras foram realizados uniformemente entre os tratamentos, de acordo com o sistema PIP, proposto pelo grupo técnico do Paraná (PIF-PR-CNPq, 2003), dentro das Normas Técnicas da Produção Integrada de Pêssego (Fachinello et al., 2003).

A coleta de folhas para a análise dos teores foliares de macro e micronutrientes foi realizada dez dias antes da colheita, tendo sido coletadas 64 folhas por parcela, conforme metodologia descrita pela Comissão de Fertilidade do Solo (1995).

A avaliação da produção foi feita com base nos frutos colhidos em sua totalidade, contados e pesados em oito plantas por parcela. A avaliação dos calibres dos frutos foi realizada apenas nas safras de 2003 e 2004, avaliando-se todos os frutos produzidos em duas plantas por parcela, os quais foram classificados, de acordo com o diâmetro, em Calibre $2(<5,0 \mathrm{~cm})$, calibre $3(5,0-5,4 \mathrm{~cm})$, calibre $4(5,5-5,9 \mathrm{~cm})$, calibre 5 $(6,0-6,4 \mathrm{~cm})$, calibre $6(>6,5 \mathrm{~cm})$.

A qualidade dos frutos foi avaliada através de análises físicoquímicas, da firmeza de polpa, sólidos solúveis totais e acidez total titulável. A firmeza da polpa foi determinada com o auxílio de um penetrômetro manual, com ponteira de oito $\mathrm{mm}$, retirando-se a casca das duas faces opostas da região equatorial da fruta, posicionando-se a ponteira perpendicularmente à polpa. Os sólidos solúveis totais foram determinados com auxílio de refratômetro manual com escala de $0-32 \%$. A acidez total titulável foi determinada de acordo com a metodologia descrita por Carvalho et al. (1990), onde $10 \mathrm{ml}$ de suco foi obtido por centrifugação da polpa de cinco frutos e diluído em $90 \mathrm{ml}$ de água destilada com três gotas de fenolftaleína a $1 \%$, titulando-se com hidróxido de sódio a $0,1 \mathrm{~N}$, até $\mathrm{pH} 8,1$. Os resultados obtidos foram analisados por meio de análise de variância, e as médias foram comparadas pelo teste Tukey, ao nível de 5\% de probabilidade.

\section{RESULTADOS E DISCUSSÃO}

Os resultados obtidos evidenciaram que as produtividades, nos três anos avaliados (Tabela 2), ficaram acima da média estadual de 9,2 $\mathrm{t} \mathrm{ha}^{-1}$, apesar da adversidade climática ocorrida no primeiro ano, provavelmente como reflexo do manejo adotado na condução das plantas, no controle de pragas, doenças e plantas invasoras, e na aplicação de corretivos e fertilizantes.

No primeiro ano, não se constatou o efeito do tratamento (Tabela 2), sendo provavelmente reflexo, em grande parte, da adubação

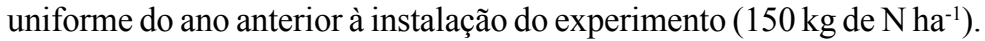
Dessa forma, verifica-se uma forte influência da adubação do ano anterior sobre a produtividade subseqüente, pois esta é definida pelo crescimento e número de ramos do ciclo anterior (Serrat et al., 2004), somado a esse efeito a ocorrência de uma geada tardia que diminuiu o potencial produtivo do pomar e, provavelmente, tenha influenciado na possibilidade de resposta à adubação de $\mathrm{N}$.

Em relação ao segundo ano, houve efeito positivo da adubação nitrogenada na produtividade das plantas (Tabela 2), confirmando a grande influência do $\mathrm{N}$ sobre a produtividade do pessegueiro, conforme constatado por Mattos et al. (1991b) e Rombolà et al. (2000). A diferença

TABELA 1 - Resultado da análise química e granulométrica, da projeção da copa entre 0-20 cm de profundidade, realizada em 2002, anteriormente à implantação do experimento (Lapa-PR).

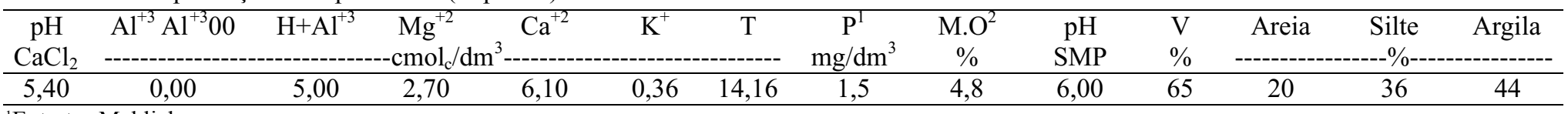

Extrator Mehlich

${ }^{2}$ Matéria orgânica 
TABELA 2 - Produção, Número de frutos e massa dos frutos, para a cultura do pessegueiro, sob diferentes doses de nitrogênio (Lapa-PR).

\begin{tabular}{|c|c|c|c|c|c|c|c|c|c|}
\hline $\begin{array}{l}\text { Dose de } \mathrm{N} \mathrm{kg} \mathrm{ha}{ }^{-1} \\
\text { ano }^{-1}\end{array}$ & \multicolumn{3}{|c|}{$\begin{array}{l}\text { Produção } \mathrm{kg} \mathrm{ha}^{-1} \\
\text { Safra } \\
\end{array}$} & \multicolumn{3}{|c|}{$\begin{array}{l}\text { Número de Frutos (planta) } \\
\text { Safra } \\
\end{array}$} & \multicolumn{3}{|c|}{$\begin{array}{c}\text { Massa do fruto }\left(\mathrm{g} \mathrm{fruto}^{-1}\right) \\
\text { Safra }\end{array}$} \\
\hline 40 & $14,0 \mathrm{ab}$ & $18,7 \mathrm{~b}$ & $19,4 \mathrm{a}$ & $221 \mathrm{a}$ & $386 \mathrm{~b}$ & $362 \mathrm{a}$ & $115 \mathrm{a}$ & $91 \mathrm{a}$ & $104 \mathrm{a}$ \\
\hline 160 & $14,7 \mathrm{a}$ & $23,2 \mathrm{a}$ & $22,6 \mathrm{a}$ & $215 \mathrm{a}$ & $505 \mathrm{a}$ & $409 a$ & $125 \mathrm{a}$ & $88 \mathrm{a}$ & $100 \mathrm{a}$ \\
\hline C.V. $(\%)^{1}$ & 29,96 & 4,47 & 18,39 & 26,74 & 3,58 & 24,60 & 23,77 & 3,82 & 7,55 \\
\hline
\end{tabular}

${ }^{1}$ C.V.(\%) Coeficiente de variação.

Médias seguidas da mesma letra, na coluna, não diferem entre si, pelo teste de Tukey, ao nível de 5\% de probabilidade.

TABELA 3 - Percentual de frutos dos diversos calibres, para a cultura do pessegueiro, nas safras de 2003 e 2004 , sob diferentes doses de nitrogênio (Lapa-PR)

\begin{tabular}{|c|c|c|c|c|c|c|c|c|c|c|}
\hline \multirow[t]{2}{*}{ Dose de $\mathrm{N} \mathrm{kg} \mathrm{ha}^{-1}$ ano $^{-1}$} & \multicolumn{10}{|c|}{ Calibres } \\
\hline & \multicolumn{2}{|c|}{2} & \multicolumn{2}{|c|}{3} & \multicolumn{2}{|c|}{4} & \multicolumn{2}{|c|}{5} & \multicolumn{2}{|c|}{6} \\
\hline 40 & $03 \mathrm{a}$ & $01 \mathrm{a}$ & $11 \mathrm{a}$ & $11 \mathrm{a}$ & $28 \mathrm{a}$ & $36 \mathrm{a}$ & $39 \mathrm{a}$ & $37 \mathrm{a}$ & $19 \mathrm{a}$ & $15 \mathrm{a}$ \\
\hline 160 & $01 \mathrm{a}$ & $01 \mathrm{a}$ & $12 \mathrm{a}$ & $08 \mathrm{a}$ & $33 \mathrm{a}$ & $47 \mathrm{a}$ & $42 \mathrm{a}$ & $35 \mathrm{ab}$ & $12 \mathrm{a}$ & $09 \mathrm{a}$ \\
\hline C.V. $(\%)^{1}$ & 4,50 & 6,74 & 11,22 & 12,83 & 28,10 & 25,38 & 16,70 & 5,49 & 28,67 & 17,28 \\
\hline
\end{tabular}

${ }^{\mathrm{I} C . V .(\%)}$ Coeficiente de variação.

Médias seguidas da mesma letra, na coluna, não diferem entre si, pelo teste de Tukey, ao nível de 5\% de probabilidade.

média de 4,5 $\mathrm{t} \mathrm{ha}^{-1}$ apresentada foi equivalente a $23 \%$, entre a maior e a menor dose aplicada (Tabela 2). Tal diferença representa quase $50 \%$ da produtividade média estadual, indicando que o decréscimo na quantidade anual de nitrogênio aplicado de $150 \mathrm{~kg}_{\text {de }} \mathrm{N} \mathrm{ha}^{-1} \mathrm{ano}^{-1}$, como o que vinha sendo utilizado pelo produtor, para $80 \mathrm{~kg} \mathrm{de} \mathrm{N} \mathrm{ha}^{-1} \mathrm{ano}^{-1}$, máxima recomendada para PIP em 2002 (Fachinello et al., 2003), poderá gerar acentuada redução de produtividade (Tabela 2).

Já para o terceiro ano, os acréscimos observados na produtividade não foram significativos (Tabela 2), embora a condição climática tenha sido favorável. A não-resposta ao uso de doses crescentes de $\mathrm{N}$ deve-se provavelmente à poda intensa, a qual uniformizou o número de frutos entre os tratamentos.

A resposta à adubação nitrogenada variou entre os anos, sendo influenciada pelas condições climáticas e de manejo do pomar. Ainda, o elevado teor de matéria orgânica no solo estudado possivelmente tenha limitado a resposta do $\mathrm{N}$ e garantido elevadas produtividades quando comparadas à média estadual. Sendo assim, o uso de doses de $\mathrm{N}$ abaixo do preconizado pelo PIP possibilita obter produtividades maiores que a média estadual, em pomar conduzido com boas condições de manejo. Mas o acréscimo acumulado de mais de $8 \mathrm{tha}^{-1}$ de pêssego, ao longo dos 3 anos, quando do uso da dose máxima comparada com a menor dose, indica favorecimento econômico a longo prazo.

O acréscimo significativo no número de frutos deu-se, apenas

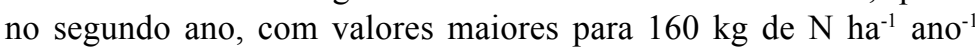
comparado com as demais doses (Tabela 2), igualmente ao observado para a produtividade, sugerindo uma relação entre esses dois parâmetros.

A análise de regressão entre número de frutos por planta $(\mathrm{x}) \mathrm{e}$ produtividade (y), envolvendo os três anos, indicou que mais de $90 \%$ da produtividade foi explicada pelo número de frutos $(\mathrm{Y}=35,8 \mathrm{X}+6038$, $\left.\mathrm{R}^{2}=0,94^{* *}\right)$. Os acréscimos no número de frutos por planta são dados pelo aumento no crescimento vegetativo, sendo certamente resultado, combinado ou isoladamente, do aumento no tamanho e número de ramos (Mattos et al., 1991b).

A massa do fruto observado nos três anos avaliados ficou próxima da massa média para a cultivar, de $100 \mathrm{~g}$ por fruto (Raseira \& Nakasu, 1998, Nienow \& Licodiedoff, 1996), não sendo influenciada pelo $\mathrm{N}$ (Tabela 2). Ainda, o acréscimo no número de frutos $(\mathrm{x})$ resultou em uma pequena redução na massa do fruto $(\mathrm{y})(\mathrm{Y}=-0,1046 \mathrm{X}+139,4$, $\left.\mathrm{R}^{2}=0,83^{*}\right)$. Resultado semelhante foi observado por Nienow \& Licodiedoff (1996), onde as maiores produtividades apresentaram frutos com massa média menor, embora a diferença fosse insuficiente para promover variação na produtividade.
Do mesmo modo que a massa do fruto, a distribuição percentual do calibre dos frutos, avaliados nos dois últimos anos, não foi afetada pela adubação nitrogenada (Tabela 3), discordando da revisão de Carvalho et al. (1989) e dos resultados obtidos por Mattos et al. (1991b). Contudo, o último autor utilizou doses maiores (até $280 \mathrm{~kg} \mathrm{de} \mathrm{N} \mathrm{ha}^{-1}$ ) e obteve produtividades equivalentes ao observado neste trabalho.

Mesmo com uma diferença de $31 \%$ no número de frutos (Tabela 2), entre a menor e a maior dose de N, para o segundo ano, a distribuição percentual do número de frutos por classes de calibre resultou em aproximadamente $70 \%$ dos frutos classificados nos calibres 4 e 5 (Tabela 3 ). Essa tendência foi confirmada para o terceiro ano, quando se repetiu a distribuição percentual entre os diferentes calibres. Logo, massa e calibre apresentaram menor importância sobre a produtividade, foram parâmetros menos influenciados pela adubação nitrogenada nas condições pesquisadas e com menor importância sobre a produtividade.

Em relação ao crescimento vegetativo dos ramos "ladrões", retirados com a poda de verão, não se observou diferença estatística para nenhum dos três anos (Tabela 4), indicando que a maior dose aplicada não promoveu supercrescimento dos ramos "ladrões", fato comum quando da aplicação excessiva de N. Esses resultados diferem dos observados por Mattos et al. (1991b) e Campos et al. (1996), que constataram aumento significativo de ramos com o aumento da adubação nitrogenada.

TABELA 4 - Massa da poda dos ramos "ladrões" no verão, em kg ha-1, para a cultura do pessegueiro, sob diferentes doses de nitrogênio (Lapa-PR).

\begin{tabular}{cccc}
\hline \multirow{2}{*}{ Dose de N kg ha ${ }^{-1}$ ano $^{-1}$} & \multicolumn{3}{c}{ Ramos "ladrões" kg ha } \\
\cline { 2 - 4 } & 2002 & 2003 & 2004 \\
\cline { 2 - 4 } & $345 \mathrm{a}$ & $295 \mathrm{a}$ & $379 \mathrm{a}$ \\
40 & $342 \mathrm{a}$ & $280 \mathrm{a}$ & $468 \mathrm{a}$ \\
80 & $468 \mathrm{a}$ & $308 \mathrm{a}$ & $606 \mathrm{a}$ \\
\hline 160 & 8,14 & 15,64 & 30,36 \\
\hline C.V.(\%)
\end{tabular}

${ }^{1}$ C.V.(\%) Coeficiente de variação.

Médias seguidas da mesma letra, na coluna, não diferem entre si, pelo teste de Tukey, ao nível de $5 \%$ de probabilidade.

Os parâmetros qualitativos sólidos solúveis totais, acidez total titulável e firmeza da polpa não foram afetados pelas doses de $\mathrm{N}$ utilizadas, para os três anos avaliados (Tabela 5), mantendo-se na faixa normal para a cultura (Argenta et al., 2004), com valores próximos aos observados por Mendonça et al. (1999) e Giacobbo (2002). Entretanto, 
TABELA 5 - Sólidos solúveis totais (SST), acidez total titulável (ATT) e firmeza da polpa (FP), para a cultura do pessegueiro, sob diferentes doses de nitrogênio (Lapa-PR).

\begin{tabular}{|c|c|c|c|c|c|c|c|c|c|}
\hline $\begin{array}{l}\text { Dose de } \mathrm{N} \mathrm{kg} \mathrm{ha}{ }^{-1} \\
\text { ano }^{-1}\end{array}$ & \multicolumn{3}{|c|}{$\begin{array}{c}\text { SST (Brix \%) } \\
\text { Safra }\end{array}$} & \multicolumn{3}{|c|}{$\begin{array}{c}\text { ATT }\left(\mathrm{cmol}_{\mathrm{c}} / \mathrm{L}\right) \\
\text { Safra }\end{array}$} & \multicolumn{3}{|c|}{$\begin{array}{c}\mathrm{FP}\left(\mathrm{lb} / \mathrm{pol}^{2}\right) \\
\text { Safra }\end{array}$} \\
\hline 40 & $8,67 \mathrm{a}$ & $11,07 \mathrm{a}$ & $8,67 \mathrm{a}$ & $5,48 \mathrm{a}$ & $10,95 \mathrm{a}$ & $5,68 \mathrm{a}$ & $13,46 \mathrm{a}$ & $14,05 \mathrm{a}$ & $12,85 \mathrm{a}$ \\
\hline 160 & $8,77 \mathrm{a}$ & $11,13 \mathrm{a}$ & $8,60 \mathrm{a}$ & $5,22 \mathrm{a}$ & $12,20 \mathrm{a}$ & $5,76 \mathrm{a}$ & $11,82 \mathrm{a}$ & $13,37 \mathrm{a}$ & $14,58 \mathrm{a}$ \\
\hline C.V.(\%) ${ }^{1}$ & 3,41 & 3,28 & 1,75 & 6,53 & 11,87 & 10,70 & 13,19 & 14,10 & 16,29 \\
\hline
\end{tabular}

${ }^{1}$ C.V.(\%) Coeficiente de variação.

Médias seguidas da mesma letra, na coluna, não diferem entre si, pelo teste de Tukey, ao nível de $5 \%$ de probabilidade.

TABELA 6 - Teor foliar de macronutrientes, em $\mathrm{g} \mathrm{kg}^{-1}$, para a cultura do pessegueiro, sob diferentes doses de nitrogênio (Lapa-PR).

\begin{tabular}{|c|c|c|c|c|c|c|c|c|c|c|c|c|c|c|c|}
\hline \multirow{3}{*}{$\begin{array}{l}\text { Dose de } \mathrm{Nkg} \\
\mathrm{ha}^{-1} \text { ano }^{-1}\end{array}$} & \multicolumn{3}{|c|}{$\mathrm{N}$} & \multicolumn{3}{|c|}{$\mathrm{P}$} & \multicolumn{3}{|c|}{$\mathrm{K}$} & \multicolumn{3}{|c|}{$\mathrm{Ca}$} & \multicolumn{3}{|c|}{$\mathrm{Mg}$} \\
\hline & \multicolumn{15}{|c|}{ Safra } \\
\hline & 2002 & 2003 & 2004 & 2002 & 2003 & 2004 & 2002 & 2003 & 2004 & 2002 & 2003 & 2004 & 2002 & 2003 & 2004 \\
\hline 40 & $32,8 b$ & $39,6 b$ & $34,9 b$ & $2,44 b$ & $2,40 \mathrm{a}$ & $1,47 \mathrm{a}$ & $24,0 \mathrm{a}$ & $21,7 \mathrm{a}$ & $16,1 \mathrm{a}$ & $13,1 \mathrm{a}$ & $12,8 \mathrm{a}$ & $13,4 a$ & $5,00 \mathrm{a}$ & $4,85 a$ & $4,67 \mathrm{a}$ \\
\hline 80 & $33,6 a$ & $40,8 \mathrm{ab}$ & $34,3 b$ & $2,62 \mathrm{a}$ & $2,32 \mathrm{a}$ & $1,43 a$ & $23,6 a$ & $21,4 a$ & $14,5 \mathrm{a}$ & $12,3 a$ & $12,1 \mathrm{a}$ & $12,2 \mathrm{a}$ & $4,80 \mathrm{a}$ & $4,82 \mathrm{a}$ & $4,53 \mathrm{a}$ \\
\hline 160 & $35,9 \mathrm{a}$ & $42,7 \mathrm{a}$ & $37,6 \mathrm{a}$ & $2,48 \mathrm{ab}$ & $2,40 \mathrm{a}$ & $1,57 \mathrm{a}$ & $23,2 \mathrm{a}$ & $20,9 \mathrm{a}$ & $15,3 \mathrm{a}$ & $13,2 \mathrm{a}$ & $12,7 \mathrm{a}$ & $11,9 \mathrm{a}$ & $4,63 \mathrm{a}$ & $5,08 \mathrm{a}$ & $4,83 \mathrm{a}$ \\
\hline C.V.(\%) & 5,10 & 2,97 & 2,49 & 2,07 & 1,41 & 3,54 & 6,55 & 6,81 & 8,62 & 5,41 & 8,60 & 7,42 & 5,33 & 4,91 & 8,08 \\
\hline
\end{tabular}

${ }^{1}$ C.V. $(\%)$ Coeficiente de variação.

Médias seguidas da mesma letra, na coluna, não diferem entre si, pelo teste de Tukey, ao nível de 5\% de probabilidade.

TABELA 7 - Teor foliar de micronutrientes, em $\mathrm{mg} \mathrm{kg}^{-1}$, para a cultura do pessegueiro, sob diferentes doses de nitrogênio (Lapa-PR).

\begin{tabular}{|c|c|c|c|c|c|c|c|c|c|c|c|c|c|c|c|}
\hline \multirow{3}{*}{$\begin{array}{c}\text { Dose de } \mathrm{N} \mathrm{kg} \\
\text { ha }^{-1} \text { ano }^{-1}\end{array}$} & \multicolumn{3}{|c|}{$\mathrm{Fe}$} & \multicolumn{3}{|c|}{$\mathrm{Mn}$} & \multicolumn{3}{|c|}{$\mathrm{Zn}$} & \multicolumn{3}{|c|}{$\mathrm{Cu}$} & \multicolumn{3}{|c|}{$\mathrm{B}^{*}$} \\
\hline & \multicolumn{15}{|c|}{ safra } \\
\hline & 2002 & 2003 & 2004 & 2002 & 2003 & 2004 & 2002 & 2003 & 2004 & 2002 & 2003 & 2004 & 2002 & 2003 & 2004 \\
\hline 40 & $63 \mathrm{a}$ & $91 \mathrm{a}$ & $87 \mathrm{a}$ & $66 \mathrm{a}$ & $67 a$ & $63 \mathrm{a}$ & $23 \mathrm{~b}$ & $20 \mathrm{a}$ & $19 \mathrm{a}$ & $6 \mathrm{ab}$ & $8 \mathrm{a}$ & $9 \mathrm{a}$ & - & $28 \mathrm{a}$ & $36 a$ \\
\hline 80 & $56 \mathrm{a}$ & $87 \mathrm{a}$ & $93 \mathrm{a}$ & $70 \mathrm{a}$ & $77 \mathrm{a}$ & $70 \mathrm{a}$ & $25 \mathrm{a}$ & $21 \mathrm{a}$ & $18 \mathrm{a}$ & $8 \mathrm{a}$ & $8 \mathrm{a}$ & $10 \mathrm{a}$ & - & $25 \mathrm{a}$ & $35 \mathrm{a}$ \\
\hline 160 & $56 \mathrm{a}$ & $94 \mathrm{a}$ & $85 \mathrm{a}$ & $58 \mathrm{a}$ & $67 \mathrm{a}$ & $67 \mathrm{a}$ & $24 \mathrm{ab}$ & $21 \mathrm{a}$ & $17 \mathrm{a}$ & $5 \mathrm{ab}$ & $8 \mathrm{a}$ & $10 \mathrm{a}$ & - & $26 \mathrm{a}$ & $36 \mathrm{a}$ \\
\hline C.V.(\%) & 5,41 & 5,41 & 18,48 & 22,64 & 20,96 & 17,05 & 14,87 & 3,25 & 9,37 & 2,03 & 2,13 & 23,93 & - & 4,91 & 4,85 \\
\hline
\end{tabular}

B não foi avaliado em 2002.

${ }^{1}$ C.V.(\%) Coeficiente de variação.

Médias seguidas da mesma letra, na coluna, não diferem entre si, pelo teste de Tukey, ao nível de $5 \%$ de probabilidade.

Carvalho et al. (1989), em revisão, mencionaram o efeito pronunciado da nutrição sobre os sólidos solúveis totais e a acidez total titulável em frutos.

Dentre os teores foliares analisados, o $\mathrm{N}$ foi afetado pela adubação nitrogenada com acréscimo no teor foliar para os três anos avaliados (Tabela 6), corroborando os resultados obtidos por Magnani et al. (1984) e Mattos et al. (1991a). Contudo, os valores de nitrogênio foliar permaneceram dentro dos níveis adequados para a cultura (Comissão de Fertilidade do Solo, 1995), indicando que as doses utilizadas não foram excessivas.

Os teores foliares dos demais elementos, exceto o $\mathrm{P}, \mathrm{Zn}$ e $\mathrm{Cu}$ para 2002, não foram afetados pela adubação, contrariando os resultados obtidos por Mattos et al. (1991a), que observaram relação inversa entre a dose de $\mathrm{N}$ aplicada e os teores foliares de $\mathrm{P}, \mathrm{K}, \mathrm{Ca}$ e $\mathrm{Mg}$. Todavia, os teores de $\mathrm{P}, \mathrm{K}, \mathrm{Zn}$ e $\mathrm{B}$ variaram entre os anos, evidenciando possíveis relações entre os teores foliares desses elementos e as condições climáticas (Tabelas 6 e 7).

Os teores de $\mathrm{Ca}$ e $\mathrm{Mg}$ ficaram abaixo do preconizado pela Comissão de Fertilidade do Solo (1995) para os três anos (Tabela 6), mesmo neste solo, que apresentava teor alto desses elementos (Tabela 1), sugerindo uma necessidade de estabelecimento de padrões locais, corroborando os resultados obtidos Mattos et al. (1991a) e Oliveira \& Tsuneta (1987). Ainda, os teores de Fe e Zn apresentaram-se também na faixa abaixo do normal (Tabela 7).

\section{CONCLUSÕES}

1. A redução na adubação nitrogenada em pomar estabelecido afetou negativamente o número de frutos e a sua produtividade no segundo ano.

2. Embora a adubação nitrogenada influencie positivamente nos teores foliares de nitrogênio, essa não interfere nos parâmetros de qualidade do fruto, mesmo quando ocorre efeito do $\mathrm{N}$ aplicado sobre a produtividade do pessegueiro.

\section{AGRADECIMENTOS}

Ao Engenheiro Agrônomo Edir Osmar Buske, proprietário do pomar onde foi instalado o experimento, ao Ministério da Agricultura, Pecuária e Abastecimento (MAPA) e ao Conselho Nacional de Apoio à Pesquisa (CNPq), pelo suporte financeiro.

\section{REFERÊNCIAS}

ARGENTA, C.A.; FLORES-CANTILLANO, F.; BECKER, W.F. Tecnologias pós-colheita para fruteiras de caroço. In: MONTEIRO, L. B.; MAY-DE MIO, L. L.; SERRAT, B.M.; MOTTAA.C.; CUQUEL F. L. Fruteiras de caroço: uma visão ecológica, Curitiba, UFPR, 2004, p.333-362.

CAMPOS, A.D.; FREIRE, C.J.S.; NAKASU, B.H.; FORTESW, J.F. Qualidade dos frutos e crescimento dos ramos de pessegueiro em função do nitrogênio e potássio foliar. In: XIV Congresso Brasileiro de Fruticultura, 1996, Curitiba. Anais... Curitiba, PR. SBF, 1996. p.379.

CARVALHO, C.R.L.; MANTOVANI, D.M.B.; CARVALHO, P.R.N; MORAES, P.R.N. Análises químicas de alimentos. Campinas: ITAL, 1990. 121p.

CARVALHO, S.A.; ROCHA, A.C.; TAVARES, E.D. Efeito dos principais nutrientes na qualidade das frutas. Revista Brasileira de Fruticultura, Cruz das Almas, v.5, n.11, p.35-44, 1989.

COMISSÃO DE FERTILIDADE DO SOLO RS/SC. Recomendações de adubação e de calagem para os estados do Rio Grande do Sul e de Santa Catarina. 3.ed. Passo Fundo, Sociedade Brasileira de Ciência 
do Solo, Núcleo Regional Sul, 1995. 224p.

BIASI, L.A.; ZANETTE, F.; PETRI, J.L.; MARODIN, G.A.B. Cultivares de fruteiras de caroço. In: MONTEIRO, L.B.; MAY-DE MIO, L.L.; SERRAT, B.M.; MOTTAA.C.; CUQUEL F. L. Fruteiras de caroço: uma visão ecológica, Curitiba, UFPR, 2004, p.5-32.

FACHINELLO, J.C.; COUTINHO, E.F.; MARODIN, G.A.B.; BOTTON, M.; LOUISE, L.M.D.M. Documento 01-Normas técnicas e documentos de acompanhamento da produção integrada de pêssego, Ministério da Agricultura, Pelotas, 2003. 92p.

FACHINELLO, J.C.; TIBOLA, C.S.; MAY-DE MIO, L.L.; MONTEIRO, L. B. Nutrição mineral de fruteira de caroço. In: MONTEIRO, L.B.; MAY-DE MIO, L.L.; SERRAT, B.M.; MOTTAA.C.; CUQUEL F.L. Fruteiras de caroço: uma visão ecológica, Curitiba, UFPR, 2004, p.363-390.

FAO, FOOD AND AGRICULTURE ORGANIZATION OF THE UNITED NATIONS. Disponível em: <http://faostat.fao.org/faostat/ form? collection=Production.Crops.Primary $>$. Acesso em 20-10-03.

GIACOBBO, C.L. Comportamento do pessegueiro (Prunus persica $\mathbf{L}$. Batsch) cv. Chimarrita em diferentes sistemas de condução, 2002. 41 f. Dissertação (Mestrado em Fruticultura de Clima Temperado), Faculdade de Agronomia Eliseu Maciel, UFP, Pelotas, 2002.

MADAIL, J.C.; REICHERT, L.J. Produção mundial e nacional de pêssego, In: RASEIRA, M.C.B; QUEZADA, A.C. Frutas do Brasilpêssego produção, Brasília, Embrapa, 2003. p.10-17.

MAGNANI, M.; FREIRE, C.J.S.; MORAES, E.C. Manejo de NPK em pessegueiro (Prunus persica (L.) Batsch, In: VII CONGRESSO BRASILEIRO DE FRUTICULTURA, EMPASC, SBF, 1984 Anais... Florianópolis, SC. v.4, p.1105-1123.

MATTOS, M.L.T.; FREIRE, C.J.S.; MAGNANI, M. Crescimento e teores foliares de $\mathrm{N}, \mathrm{P}, \mathrm{K}, \mathrm{Ca}$ e $\mathrm{Mg}$ em pessegueiro cv. Diamante com diferentes níveis de $\mathrm{N}$ aplicado ao solo, Pesquisa Agropecuária Brasileira, Brasília, 26(9), p.1315-1321, set. 1991a.

MATTOS, M.L.T.; FREIRE, C.J.S.; MAGNANI, M. Produção do pessegueiro cv. Diamante, sob diferentes doses de nitrogênio aplicado ao solo, Pesquisa Agropecuária Brasileira, Brasília, 26(1), p.113-117, jan. 1991b.

MENDONÇA, L.I.; MACHADO, L.B.; CORRENT, A.; CHAGAS, E.A.; FACHINELLO, J.C.; FARIA, J.L.C. Produção e qualidade de pêssegos em diferentes sistemas de cultivo, Revista Brasileira de Fruticultura, v.5, n.2, p.86-88, 1999.
MOTTA, C.V.M.; SERRAT, B.M.; FAVARETTO, N. Fertilidade do solo. In: MONTEIRO, L.B.; MAY-DE MIO, L.L.; SERRAT, B.M.; MOTTA A.C.; CUQUEL F. L. Fruteiras de caroço: uma visão ecológica, Curitiba, UFPR, 2004, p.49-57.

NIENOW, A.A.; LICODIEDOFF, M.A. Comportamento fenológico e produtivo de cultivares de pessegueiro e nectarina do planalto médio do Rio Grande do Sul, Revista Brasileira de Fruticultura, v. 18, n.2, p.201-208, 1996.

Normas de Produção Integrada de Pêssego (PIP): versão II. Pelotas: Ed. UFPEL/EMBRAPA/UFRGS/URCAMP, 2001. 52p.

OJIMA, M.; ORTO, F.A.C.D.; BARBOSA, W.; RAIJ, B.V. Frutas de clima temperado: I ameixa, nectarina e damasco japonês (umê). In: Instituto Agronômico de Campinas. VAN RAIJ, B.; QUAGGIO, G.A.; FURLANI. A.M.C. Boletim 100 Recomendações de adubação e calagem para o estado de São Paulo, Fundação IAC, 2 ed., 1997, p.138.

OLIVEIRA, E.L.; TSUNETA, M. Estado nutricional do pessegueiro na região metropolitana de Curitiba. Informe da Pesquisa, IAPAR, n.79, nov. $1987,8 \mathrm{p}$.

PEREIRA, F.M.; COUTINHO, E.L.M.; OLIVEIRA, F.Z. Importância da adubação na qualidade das frutas de clima temperado, In: Sá, M. E.; BUZZETTI, S. Importância da adubação na qualidade dos produtos agrícolas, São Paulo, 1994. p.161-175.

PIF-PR-CNPq. 2003. Produção Integrada de Pêssego para o Estado do Paraná, Relatório Técnico enviado ao CNPq, UFPR.

RASEIRA, M. do C.B.; NAKASU, B.H. Cultivares: descrição e recomendação, In: MEDEIROS, C.A.B.; RASEIRA, M.C.B. A cultura do pessegueiro, Brasília, Embrapa, 1998, p.36-37.

REEVES, J.; CUMMINGS, G. The influence of some nutritional and management factors upon certain physical attributes of peach quality. Journal of the American Society for Horticulture Science, v. 95, p.338-341, 1970.

ROMBOLÀ, A.D.; TOSELI, M.; SCUDELLARR, D. A nutrição das frutas de caroço na fruticultura ecocompatível, IN: Simpósio internacional de frutas de caroço pêssegos, nectarinas e ameixas, 2000, Porto Alegre. Anais... Porto Alegre, RS, UFRS, p.41-60, 2000.

SERRAT, B.M.; REISMANN, C.B; MOTTA, A.C.V.; MARQUES, R. Nutrição mineral de fruteira de caroço. In: MONTEIRO, L.B.; MAYDE MIO, L.L.; SERRAT, B.M.; MOTTA A.C.; CUQUEL F.L. Fruteiras de caroço: uma visão ecológica, Curitiba, UFPR, 2004, p.71-95. 